\title{
A Reversionary Character in the Stock (Matthiola incana) and its Significance in regard to the Structure and Evolution of the Gynoecium in the Rhoeadales, the Orchidaceae, and other Families.
}

\author{
EDITH R. SAUNDERS, \\ Fellow of Nerenham College, Cambridge. \\ With sixty Figures in the Text.
}

\section{Contents.}

I. Introduction. The Cruciferous gynoecium . . . . . . . . . 45 I

2. Appearance and structure of a typical siliqua in the Stock . . . . . . . $45^{2}$

3. Interpretation of the siliqua construction . . . . . . . . . . . 455

4. Exceptional forms of siliqua in the Stock . . . . . . . . . . 457

5. Conclusions that the typical siliqua is the outcome of a process of reduction and consolidation, and that the formula should be $\mathrm{G}_{4}$, the carpels being dimorphic . . . . . 460

6. The conception of the dimorphic carpel removes the anomaly of the false partition and the commissural stigma, and brings into harmony and renders intelligible many facts hitherto unexplained or without significance . . . . . . . . . . . . $4^{6} 3$

7. Reduction and consolidation shown to have occurred in like manner in the Papaveraceae, Fumariaceae, Capparidaceae, and Resedaceae . . . . . . . . 469

8. A cursory survey of the Ericales, certain Malvaceae, and some isolated genera which are held to have commissural stigmas, leads to the same conclusion. ${ }^{1}$ The commissural stigma also not a reality in the Orchidaceae, the gynoecium being composed of six carpels $(\mathrm{G} 3+3)$

9. Summary of Conclusions .

\section{Introduction. The Criciferous gynoccium.}

THE composition of the Cruciferous gynoecium has been the subject of much discussion in the past, the chief points at issue being the real number of the carpels and the nature of the replum. My attention was originally directed to this question in consequence of the repeated appearance in the Stock of fruits of unusual shapes. Some were found with a longitudinal flange or wing-like structure extending the whole length and

1 It is proposed to treat of these cases in detail in a later account.

[Annals of Botany, Vol. XXXVII. No. CXLVII. July, 1923.] 
often showing deep transverse fissures as though the tissues had been torn across. Others, though exhibiting no sign of injury, were curved instead of straight, or in extreme cases coiled into a spiral like the pods of certain Leguminosae. A fuller examination of these fruits yielded the results set forth in the present account.

\section{Appearance and structure of a typical siliqua in the Stock.}

The chief external feature of the developing Stock siliqua is the outline of the valves indicating the place of separation from the replum ${ }^{1}$ of the two laterally placed carpels when ripe. These outlines are somewhat obscured in the hoary type by the dense covering of hairs, but in the glabrous strains they are clearly defined, and for this reason these strains offer particularly favourable material for the investigation of the points above mentioned. The ovary shows the usual two valves. Between them, in the median plane, is the somewhat broad tract (commissure) regarded as formed from the conjoined carpellary edges (Fig. I), the inward extensions of which give rise to the placentae, and ultimately become joined at their extremities and so form a complete septum. These two intervening tracts can be seen to swell out at the top of the siliqua into two large connivent knobs or horns (Fig. 2), which may eventually touch (Figs. 5, 6). The valves themselves are defined above in the developing fruit by a horizontal ridge (Figs. 3, 7), which may merge imperceptibly into the knobs or be delimited from them by a continuation of one or both of the sutural lines (Fig. 8). Above this ridge the two flat surfaces slope backwards (inwards) for a short distance and are covered at their summit by the stigmatic papillae. In the young stage the commissures are so narrow that the papillae appear to be continuous round the dividing cleft, and it may be that the ring is sometimes completed by the formation of papillae over the sutures as well as on the valves. But the fruits occasionally to be met with, in which the carpels become free from each other at the apex (Figs. 9, 10), make it clear that the two main stigmatic areas are centred over the midrib of each lateral carpel; that is to say, they are not commissural, as is stated to be the arrangement in the Cruciferae generally, but alternate with the placentae and replum. As post-fertilization development proceeds, the stigmatic bands between the swelling terminal knobs become $\mathbf{V}$-shaped, the double $\mathbf{V}$ now bordering a shallow, bluntly 4-angled, crater-like cavity which may be considered a short stylar canal (Fig. 4). Later still this cavity becomes narrowed into a double loop or figure of 8 extended crosswise between the pincer-like knobs. Such is the outward appearance of normal fruits.

To the internal structure of the siliqua but little attention seems to have been paid by earlier observers, beyond notice of the presence or absence of

1 The term replum is used throughout the present account in its wider sense to include both the frame of the placentae and the partition stretching between them. 



3
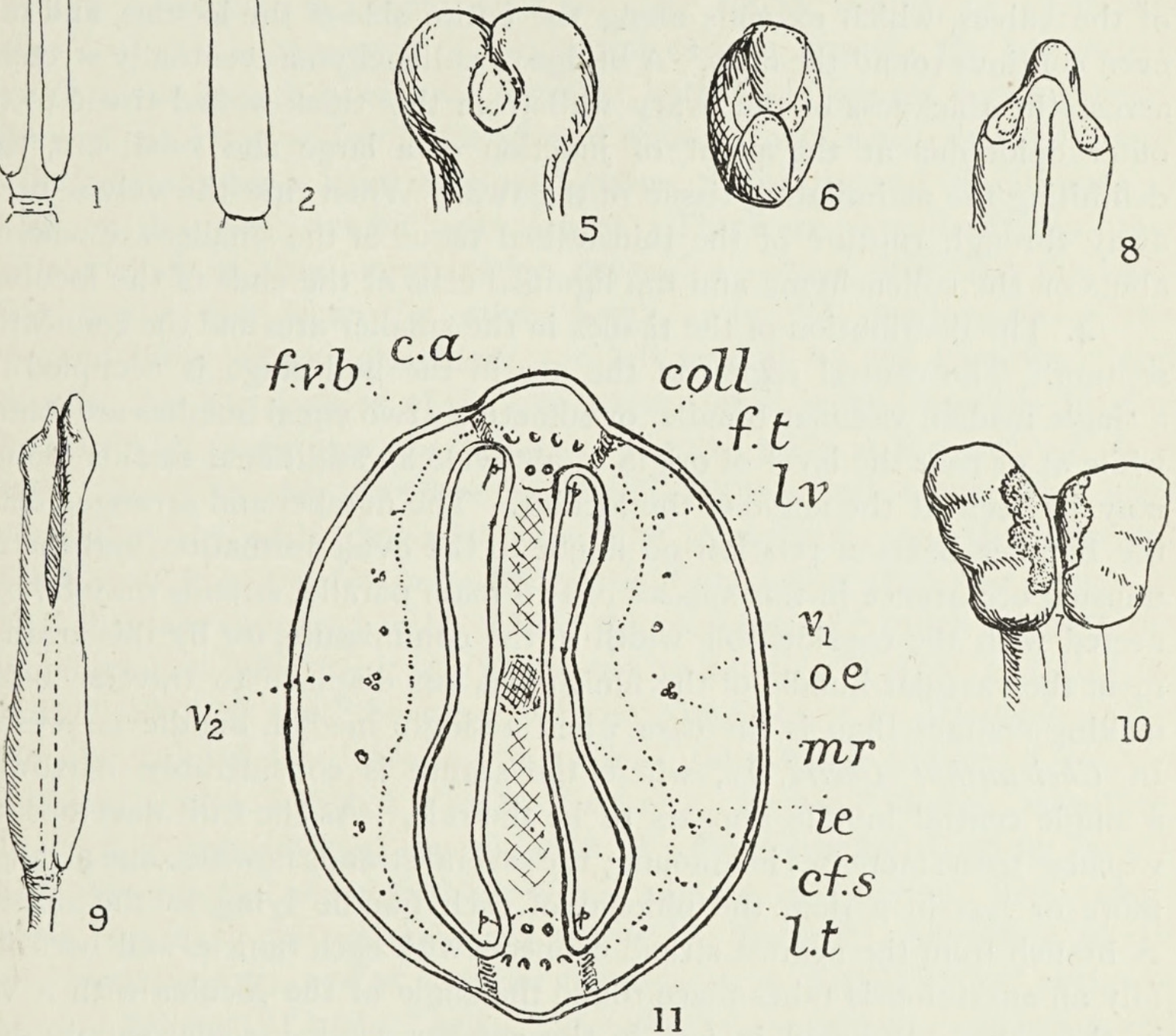

Figs. I-II. Matthiola incana. I. Young siliqua before fertilization viewed from the front, showing the double contour line of the suture, and crosswise to the suture the two stigmatic loops. 2. Young siliqua shortly after fertilization viewed from the side, showing one valve and development of the sutural knobs. 3. Apex of siliqua seen from the front, showing the horizontal ridge delimiting the valves. 4. The same seen from above, showing the short stylar canal. 5. A later stage seen from the side; the sutural knobs have now met. 6 . The same seen from above. 7 . Intermediate stage seen from the side, showing the ridge defining the valve. 8. Apex of a siliqua in which the sutural lines are continued up on to the shoulders of the knob. 9. Siliqua in which the carpels are disjoined above, seen from the front. Io. Apex of a similar siliqua seen obliquely from above and from the front. II. Transverse section of young siliqua. c.a., commissural arc; $v_{1} v_{2}$, valves; coll., collenchyma : cf.s., central fibrous strand; f.t., fibrous tissue: f.v.b., fibro-vascular bundles of the commissure ; i.e., inner epidermis; l.t., loose tissue of the septum which later becomes lignified ; l.v., lateral veins; m.r., midrib of valve; o.e., onter epidermis; $p$., position of placenta. 
a central fibrous strand in the septum, a character regarded by systematists as of diagnostic value. In Matthiola incana, $\mathrm{R}$. Br., the main features to be noted in a transverse section of the developing siliqua are as follows (Fig. II):

I. The outer contour, which shows two larger lateral arcs formed by the two valves, and two intervening smaller arcs (commissures) bounding the ends of the single median partition.

2. The central larger fibro-vascular bundle (midrib) of the valves, and the row of smaller bundles (lateral veins) on either side of it.

3. The broad belt of lignified cells beneath the inner (lining) epidermis of the valves, which extends along the entire side of the loculus, and may even continue round the ends. A bridge of collenchyma eventually stretches across the thickness of the ovary wall from this thick-walled tissue to the outer epidermis at the point of junction of a large and small arc, thus delimiting the assimilating tissue of the two. When ripe the valves break away through rupture of the thin-walled tissue of the smaller arc where it abuts on the collenchyma and the lignified cells at the ends of the loculus.

4. The distribution of the tissues in the smaller arcs and the connecting septum. The central region of the arc in the bud stage is occupied by a single median vascular bundle, or sometimes two equal bundles are found, ${ }^{1}$ while at or near the level of origin of an ovule an additional smaller bundle may be seen at the angle of the loculus. The number and arrangemert of the bundles bears a relation no doubt to the ovule formation, and the not unusual occurrence in this species of two main parallel strands may be connected with the considerable width of the commissure, for by this arrangement the vascular bundle of the funicle has less distance to traverse before making contact than is the case when a single median bundle is present. In Cheiranthus Cheiri, L., where the suture is considerably narrower, ${ }^{2}$ a single central bundle appears to be the rule. As the fruit develops, the vascular tissue increases in amount; the several strands now become arranged more or less in a ring, the phloem of each bundle lying to the outside. A branch from the nearest strand connects with each funicle, and occasionally an anastomosis takes place round the angle of the loculus with a vein in the valve. We find in fact in the smaller arc a vascular supply quite equal to that of the valve, but compressed into a smaller area, the bundles lying on a small circle instead of an extended arc. Conversion of the neighbouring ground tissue into mechanical tissue eventually gives rise to a solid fibro-vascular cord. This cord is surrounded by thin-walled, loosely arranged cells, containing a little chlorophyll, which form the outer (basal) end of the septum. Following upon but sharply marked off from this looser

1 The two conditions may occur at different levels in the same septum.

2 The considerable width of the commissure in Matthiola as compared with Cheiranthus is well seen in the drawings of the cross-section of the siliqua of these two genera in Reichenbach's Icones, ii, Pl. XLV. 
tissue, and forming the farther central end, are larger, colourless, elongated, irregularly shaped cells, which later also become thick-walled and lignified. The two ingrowing septa eventually meet, the lining epidermis disappears from the two contact surfaces which unite, and the partition is complete. Later the cells at the point of junction become converted into a longitudinal strand of fibres, a character of importance from the systematic point of view.

\section{Interpretation of the siliqua construction.}

The commonly accepted view of the Crucifer siliqua, as mentioned above, is that it is composed of two lateral carpels forming the two valves, and that the two smaller arcs, together with their inward prolongations, represent the incurved fertile margins of these carpels, which finally become united centrally by a later developed tissue, the origin and significance of which, on this view, remain unexplained. There are also admittedly other features which on this interpretation present a certain difficulty, the chief being firstly, that when the valves break away the small arcs, i.e. the supposed fused edges (placentae), are left behind on the partition; and secondly, that the position of the two stigma lobes, when these are distinct, is in nearly all cases over the sutures. Thirdly, there is the fact, which is clearly shown in the drawings of Payer, Eichler, and others who have investigated the early development of the gynoecium, that the placental commissures from the first moment of origin are larger than the carpels of which they are supposed to be merely the margins. In order to meet the stigma-position difficulty it was suggested by Lindley ${ }^{1}$ (I828) and also by Kunth ${ }^{2}(\mathrm{I} 83 \mathrm{I}-3)$ that the supposed conjoined edges or placentae really represent independent carpels, the siliqua thus being composed of four members, a view adopted also by Godron. ${ }^{3}$ Eichler, ${ }^{4}$ though admitting that certain appearances, especially in the Papaveraceae-another family which presents the same problem-lend support to Lindley's idea, nevertheless regards it as preferable to accept R. Brown's ${ }^{5}$ conception of the commissural stigma, and to consider the number of carpels in the Cruciferae as two. Benecke, ${ }^{6}$ Chodat, ${ }^{7}$ and Celakovsky, ${ }^{8}$ surveying the arguments and evidence afresh, have severally endorsed Eichler's formula, either expressing the opinion that the construction of the Cruciferous flower is dimerous throughout (Benecke and Celakovski) or that the full gynoecium ground-

1 Bot. Register, vol. xiv (= vol. i of 2nd series), text accompanying Pl. II68 (Eschscholzia californica).

${ }^{2}$ Handbuch der Botanik; also Über die Blüthen- und Fruchtbildung der Cruciferen.

${ }^{3}$ Ann. Sci. Nat., Bot. v, $2^{\mathrm{e}}$ sér., p. $293 . \quad{ }^{4}$ Blüthendiagramme, ii, p. 192.

${ }^{5}$ Pl. Jav., note, p. Io8.

${ }^{6}$ Zur Kenntniss des Diagramms der Papaveraceae und Rhoeadinae (Engler's Bot. Jahrb., ii, 1882 ).

* Neue Beiträge zum Diagramm der Cruciferenbl üthe (Flora, 1xxi, 1888).

8 Das Reductionsgesetz der Blüthen (Sitzb. d. K. Böhm. Ges. Wiss., No. 3, I894). 
plan is never realized, two members being always suppressed (Chodat). And so $\mathrm{G}_{2}$ it has remained. Arguments in favour of a 4-membered whorl have, it is true, been advanced by Schmitz, ${ }^{1}$ but they are urged in favour of a schematic rather than an actual ground plan: $\mathrm{G}_{4}$ stands, not for the siliqua as it is, but for an abstraction, the concern of the author being to realize a common generalized diagram for all Dicotyledons (!). Somewhat later Kerner, ${ }^{2}$ regarding the placental commissures as arising after the valves and forming a second inner whorl, definitely ranged himself as a supporter of Lindley's view that they represent whole carpels. But this premise was directly opposed to the statements of both Payer and Eichler, and current opinion remained unchanged. A distinct advance in knowledge is, however, reached by the observations of Klein ${ }^{3}$ upon the course of the vascular bundles. He concludes that in the case of what he calls 'open' flowers the course of the four bundles destined for the four longer stamens indicates a true diagonal position for these members, and that only in flowers with petals clawed to accommodate the nectaries do they approximate to the median plane. In accord with the conclusion that the four longer stamens represent a true tetramerous whorl, he holds that there are four carpels in the gynoecium, two of which form the replum, basing this view again on the course of the bundles and on the fact that nowhere else do the meeting edges of carpels develop such a considerable amount of fibrovascular tissue as is to be found in the replum of the Cruciferae. Both arguments afford strong grounds for belief, but the outline needs to be extended and the blanks to be filled in if the picture is to be convincing.

One feature especially conspicuous in glabrous strains of Matthiola incana, R. Br., which has always appeared to me difficult to reconcile with the view generally held, is the considerable and often varying width of the tract of tissue (commissure) separating the valve boundaries, ${ }^{4}$ a difficulty which does not become less after examination of the internal structure. It was, however, only after investigation of a number of fruits of the exceptional type mentioned above (p. 451) that the true nature of this tract was apprehended. It then became clear that the accepted formula $\mathrm{G}_{2}$ did not fit all the facts observable in this species. On the other hand, these appearances, and various records by other observers of similar occurrences in other Cruciferous genera, could all be brought satisfactorily into line on the supposition that the minimum number of carpels in the siliqua is not two but four, and that the full number in the exceptional fruits is eight. A con-

${ }^{1}$ Die Familien-Diagramme der Rhoeadinen (Abh. Naturf. Ges. Halle, Bd. xiv, 1878).

2 Pflanzenleben, ii, 189 I, p. $68_{3}$.

${ }^{3}$ Der Bau der Cruciferenblüthe auf anatomischer Grundlage (Ber. d. deut. Bot. Gesell., xii, 1894).

4 The difficulty of regarding the commissures merely as placentae appears fully as great in Sisymbrium pannonicum, Jacq., where the disparity in width of valves and commissures is still less. (See Reichenbach, Icones, ii, Table LXXIV, Fig. 4406.) 
sideration of the facts set forth below will show the grounds upon which this statement is based.

Variously curved and coiled fruits had been noticed in the Stock in successive seasons, but their appearance was so suggestive of the kind of unilateral injury so often caused by insects and other agencies that no close examination of them was made until their abundance in the exceptional season of I92I attracted attention afresh. It was then seen that their asymmetric shape was not due to accidental lesion but to an unusual anatomical construction. It was furthermore found that this structural variation was sometimes, though more rarely, symmetrical, the siliqua then remaining straight. A description of some of these cases will serve to make clear the nature of these anatomical peculiarities.

\section{Exceptional forms of siliqua in the Stock.}

I. The siliqua is 4-valved, with four sometimes rounded but more often flat or concave sides and a small arc at each angle. trilocular, with two complete partitions in planes parallel to each other and to the median plane. The valve edges are not incurved and are not utilized in the formation of the septa, which are developed entirely from the small arcs. ${ }^{1}$ Ovules arise on either side and at each end of each septum, but probably not more than three or four of these eight placentae ever mature seed. There are four stigmatic surfaces separated by four knobs, one at each corner, the stigma of each valve forming a loop, or those of the median pair remaining straight. If, as may happen, one side of the siliqua is rather more strongly developed. than the other the septum joining the commissural arcs on the weaker side may not be formed. If the development is very unequal the fruit becomes spirally coiled (Figs. I 2-I 8 ).

2. The siliqua is bluntly 4-angled, with the anterior and posterior surfaces often flat or concave. In the lower region there are two commissures of normal appearance, i. e. each is defined by two contour lines. About one-quarter up the length of the siliqua one commissure broadens out, and a small valve is interpolated which is continued up to the top. A cross-section through the lower region shows one normal convex lateral valve in contact on either side with a small arc (commissure). The one arc has the usual vascular supply; in the other two vascular cords are present. It is in this latter suture that the small new valve is developed higher up, between the two fibro-vascular strands which have now diverged. The

1 In this connexion it is interesting to note that just a century ago, on grounds which he formulates, Lestiboudois expressed himself on this point thus: 'I do not believe that the edges of the valves turn in to form the septum' (Mémoire sur les Fruits siliquenx). His belief was well founded. In regard to this point the schematic diagrams for the Rhoeadales in which such incurving is invariably represented are misleading. They represent not a reality but an abstract conception which. is in fact erroneous. 
circumference of the section is completed by two normal-sized valves forming a blunt angle but no external suture along the line of fusion, which is without vascular elements. Thus throughout a considerable part of its length the siliqua is constructed of four valves with three intervening commissures (Fig. I9). - The stigma configuration, as one would expect in these circumstances, is asymmetrical. The one commissure forms a typical large knob; of the other two on either side of the interpolated valve, the one forms a small knob, the other a barely perceptible swelling. A more symmetrical type of construction was observed by de Candolle ${ }^{1}$ in a fruit of the Wallflower, of which he gives figures as seen whole and in cross-section. The drawings show four valve carpels, one of which is free from the others, and (apparently) only two small arcs. (The fact that the vascular strands are not represented leaves it uncertain whether the two missing arcs were suppressed wholly or in part, or whether they were exceptional in containing two vascular strands which separated as the tissue split and the one valve became free, so that each remained attached to the margin of a neighbouring valve.)

3. The siliqua is three-sided, with one unpaired valve in the lateral plane and two equal valves converging to an opposite point, most frequently curved into a half-circle, but sometimes straight or nearly so, with two normal sutures and in place of the third a sharp-angled edge becoming ragged later and often torn across. ${ }^{2}$ Of the three valves, the lateral one is at a lower level and strongly convex on the outer surface; the other two stand at a slightly higher level and are flat or even concave. A normally formed partition usually connects the two small arcs on either side of the one lateral carpel, so as to form a fertile loculus. The other two valves often bulge so much on their inner face as to meet at the midribs and thus form a second false loculus, but on their contiguous margins they produce no placentae. These latter edges may remain confluent, forming a knifeedge; or they may prematurely separate for a longer or shorter distance, diverging so as to expose their inner face either completely, or up to the line of their coalescent midribs, their margins showing a clean split ; or they may become free but remain in close juxtaposition, presenting a ragged appearance which is often further emphasized by transverse fissuring, followed by drying up of the exposed tissue. The stigmatic arrangement is in accord with this configuration. The two median commissures usually end in fair-sized knobs. On one side of these knobs is the loop of stigmatic papillae crowning the lateral valve, on the other the two parallel crests of

1 Monstruosités végétales (in Nouveanx Mémoires de la Soc. Helvétique des Sci. Nat., v, I 84 I, Tab. V, Figs. 8, I3).

2 A precisely similar appearance in the frnit of the Wallflower is depicted by Schlotterbeck (Acta Helvetica, ii, Tab. II, Fig. I6), and there is little doubt that the sickle-shaped siliqua on the Stock plant which served Besler for his drawing in Hortus Eystettensis (Cl. Aestivalis, fol. 33, ii) was derived from a 3 -valved gynoecium. 

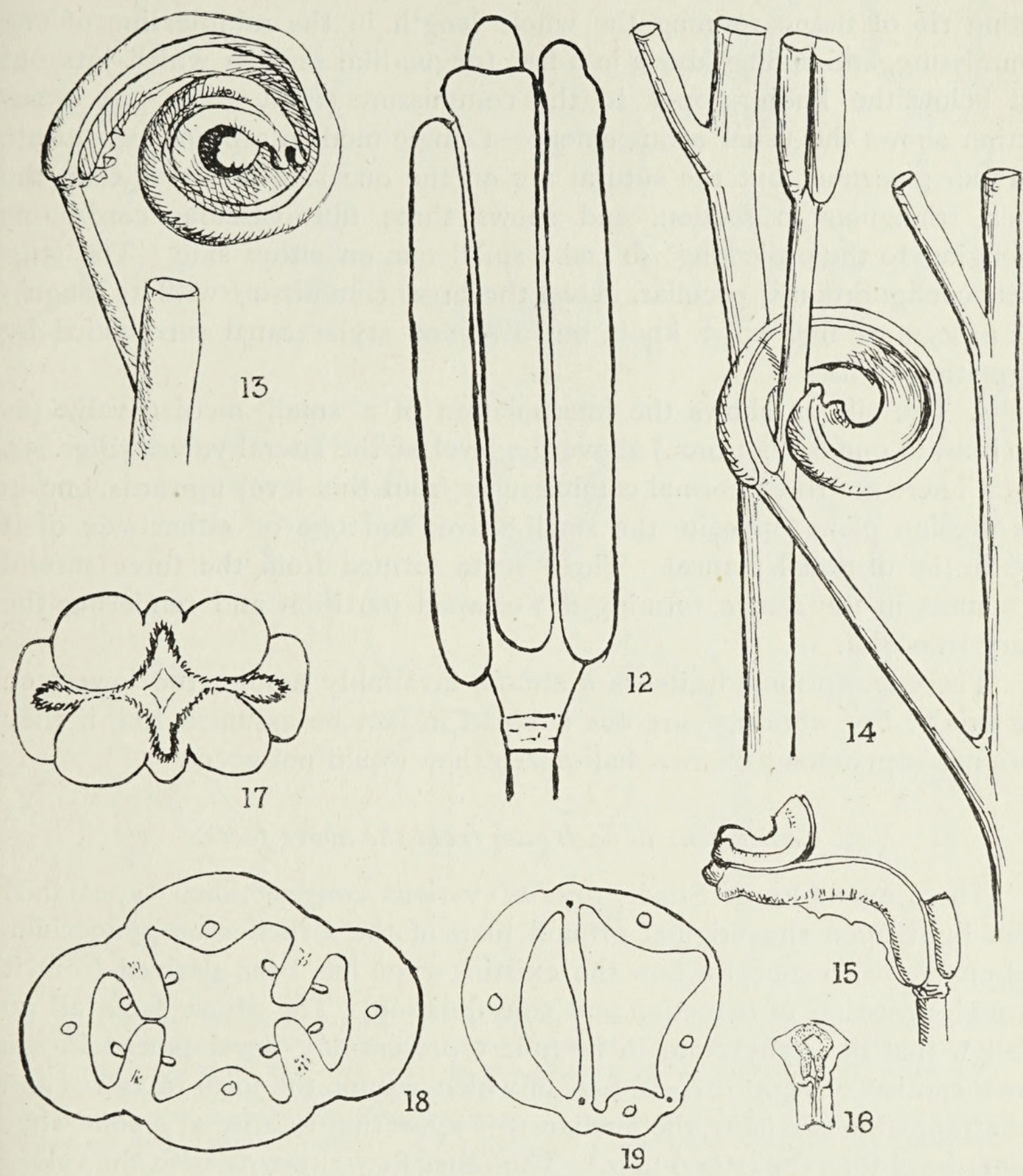

FIG. I 2-I9. Matthiola incana. 12. A straight 4-valved siliqua slightly asymmetrical with four orthogonal valves and four diagonal commissures. I3, I4. Two coiled 4-valved fruits; the lateral valve on the one (concave) side imperfectly developed with ruptured edges, hence the spiral form of the siliqua. 15. A small 4 -valved siliqua with four orthogonal valves, of which the two median show rupture of the tissues, one being torn completely across. I6. Apex of the same, showing the stigmatic area formed by three of the valves; the fourth valve ends a little below without forming a stigma. 17. (Semi-diagrammatic.) Apex of a symmetrical 4-valved siliqua, showing the four sutural knobs, the outline of the two lateral valves right and left, the central cavity, and the stigmatic surfaces forming a double figure of 8 . I8. Transverse section of a young 4-valved siliqua, showing the formation of two septa by the four diagonal solid carpels. I9. Transverse section of a siliqua composed of four valves and three commissures. 
the paired valves, for as no knob is developed over the knife-edge suture these latter are not compressed into loop form (Figs. 20-9).

4. The siliqua, though 2-valved, is somewhat curved, and has a projecting rib of tissue running the whole length in the middle line of one commissure, and ending above in a free tongue-like process which juts out just below the knob proper to the commissure (Figs. 30-3). A crosssection shows the usual arrangement-a single median septum, two loculi, and four placentae, but the sutural arc on the one side is larger than the other, triangular in section, and shows three fibro-vascular cords, one belonging to the projecting rib and a small one on either side. The stigmatic configuration is peculiar. Over the larger commissure with its tonguelike process we find not a knob, but a second stylar canal surrounded by stigmatic papillae.

5. The siliqua shows the interpolation of a small median valve (as much as, in one case, $3 \mathrm{~mm}$.) above the level of the lateral valves (Figs. 34 , 35). There are three normal commissures from this level upwards, one in the median plane opposite the small valve, and one on either side of it (i. e. in the diagonal planes). Three septa formed from the three sutural arcs meet in the centre, forming a $\mathbf{Y}$-shaped partition and rendering the ovary trilocular.

These exceptional fruits were almost invariably among the lowest on the axis. ${ }^{1} \quad$ For working purposes it could in fact be assumed that if they were not seen among the first half-dozen they would not occur.

\section{Conclusions to be drawn from the above facts.}

These examples of Stock fruits of various constructional types shed fresh light upon the original ground plan of the Cruciferous gynoecium, and enable us to conceive how the existing type has been derived from it through processes of reduction and consolidation. The above facts all go to show that the gynoecium in its fullest present-day development in the Stock consists of eight carpels, four of which assume the form of valves and are arranged in two pairs, the median pair appearing to arise at a somewhat higher level than the lateral pair. ${ }^{2}$ The other four alternate with the valves as though the latter constituted a single whorl, in precisely the same manner as the four petals alternate with the two pairs of sepals. These latter carpels are solid, compressed into the small space between the valves, and appear outwardly as broad or narrow commissures. They are almost invariably fertile, whereas the hollow (valve) carpels are probably only so in

1 See also Peyritsch, Pringsheim's Jahrb., viii, 1872 , p. II 7 . It is in flowers in this position that other exceptional constructions seem most frequently to occur, as e. g. 'twinning' (see Journ. of Genetics, vol. xi, 1921, p. 69), and the formation of extra stamens $(7-8)$.

${ }^{2}$ It is not, however, always the case that the level of swelling out into valve shape indicates the true level of origin (see Cases 2 and 5 above). 

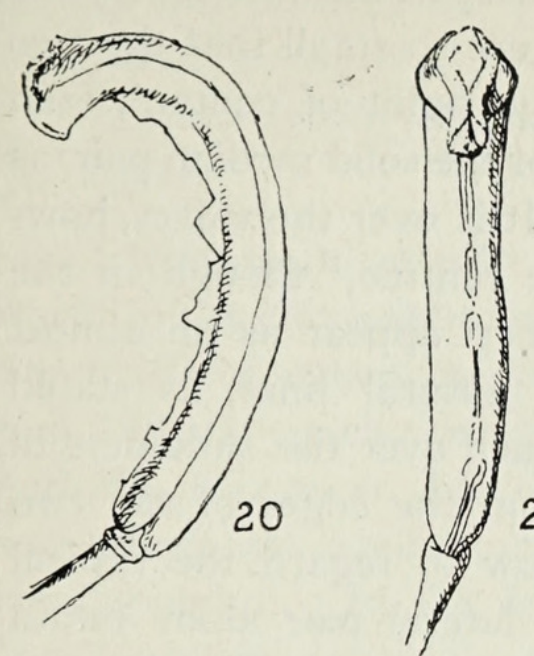

21
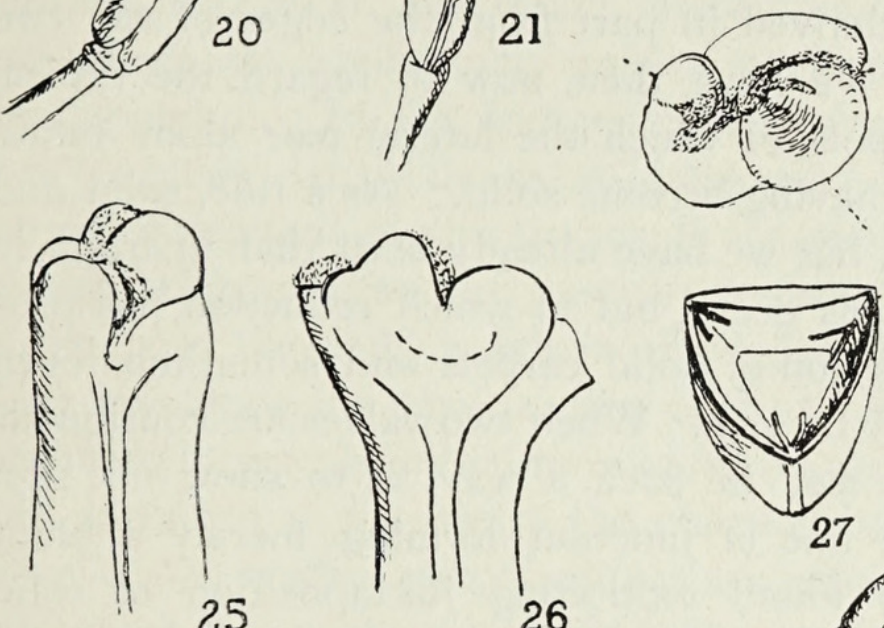

25

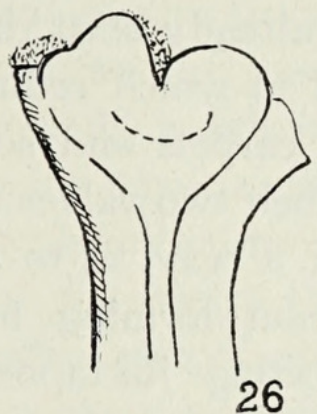

26

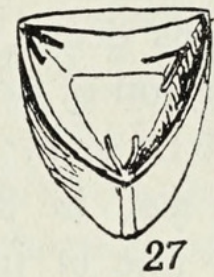

27
22

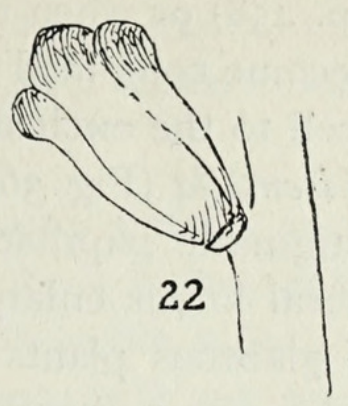

24

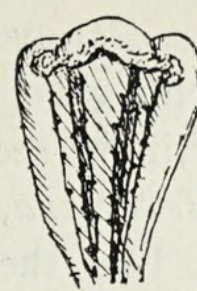

23



34

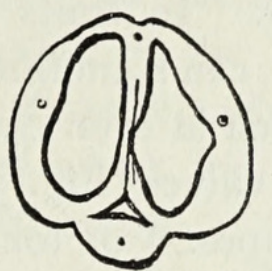

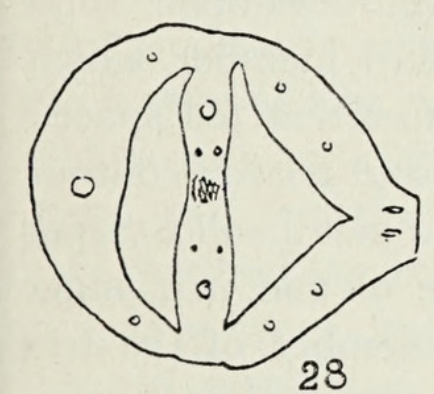

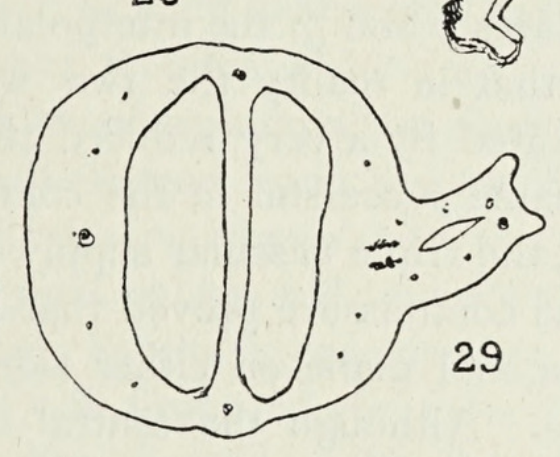

35
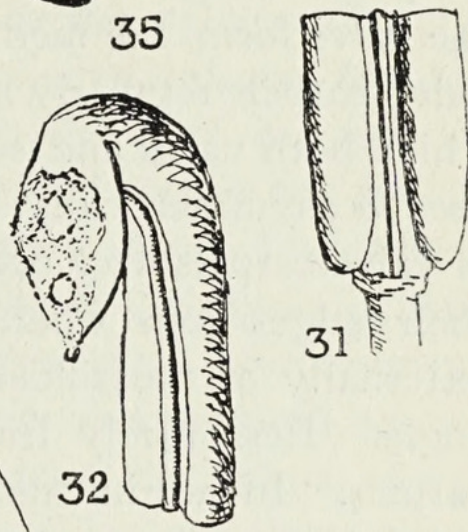

\section{1}

FIGS. 20-35. Matthiola incana. 20. A curved 3-valved siliqua with one lateral valve on the convex side and one of the pair of diagonal valves with ruptured edges on the concave side. 2I. A similar 3 -valved fruit seen from the side, showing partial rupture of the edges of the two diagonal valves. 22, 23. Very young 3 -valved siliqua with the two diagonal valves completely disjoined. 22. Seen from the side of the lateral valve. 23. Seen from the opposite side, showing the disjunction of the diagonal valves. 24-6. Apex of a 3 -valved siliqua with valves disjoined at the apex. 24. Seen from above, the dotted lines indicate the positions of the three commissures. 25,26 . Different views of the same seen from the side. 27. Transverse section of a symmetrical fruit with three valves and three commissures. 28. Transverse section of a siliqua with one lateral and two diagonal valves which have fused at their mid-ribs and formed a wing (cut away). 29. Transverse section of a similar siliqua; the two diagonal valves after fusing at their mid-ribs have separated again for a short distance and then reunite to form a two-winged edge. 30. A 2-valved siliqua, seen from the side, with a projecting rib extending the whole length of one commissure and terminating just below the sutural knob in a short process. 3I. Lower end of the same siliqua seen from the front, showing the rib in the centre of the commissure. 32. Upper end of the same, showing the stigmatic area; a second small cavity (stylar canal) has been formed over the projecting rib. 33. Transverse section of the same siliqua, showing a triarch outline to the commissure carrying the projecting rib and three vascular cords. 34. Lower end of a siliqua, showing the development of a median valve $3 \mathrm{~mm}$. above the lateral valves. 35. Transverse section of the same, showing the development of a small third loculus corresponding to the median valve. (The small vascular bundle in each of the front commissures is not shown.) 
exceptional circumstances, as e.g. when the solid carpels are lacking (if this condition occurs, see above, p. $45^{8}$ ) or when they are so small that the two edges of each lateral valve become conjoined at the point of contact, each thus forming a fertile closed cell to the exclusion of the solid median pair, as in Menonvillea, Hexaptera, Biscutella (Fig. 36). It is over the valves, however, in the Stock that the stigmatic papillae are centred, ${ }^{1}$ though in the young siliqua before the sutural knobs enlarge they appear as an almost complete ring. In fruits of glabrous plants the sutural lines, as stated above (p. 452), can sometimes be seen to be continued over the shoulders of the knob, which in such case is derived in part from the edges of the two neighbouring valves (Fig. 37). We have, then, now to regard the typical siliqua as composed of four carpels, of which the lateral pair alone retain the valve form, the median pair having become solid. As a rule, solid and valve carpels regularly alternate, but we have already seen that in fruits in which both valve and solid carpels occur, but in which reduction has proceeded asymmetrically, juxtaposition of solid carpels and sometimes even of valve carpels may occasionally be seen. When two valves are contiguous their edges join where they meet in such a way as to show no sign externally of the soldering, the line of junction forming merely a blunt angle. Less rarely fruits were found exhibiting juxtaposition of solid carpels. In two instances (Cases 2 and 5) the interpolation of a valve part way up the siliqua showed that in reality the two well-developed solid carpels must have been separated by a very reduced third member, which assumed valve form as it became successful in the competition for space. ${ }^{2}$ In another, however (Case 4), the triple vascular supply and triarch contour line of the cross-section of one commissure proved that a small solid carpel had been formed in each diagonal plane on either side of and in contact with one solid median carpel. Although the central member of the trio got as far as forming a projecting rib of tissue, it did not attain to valve form. We find in fact that the symmetrical alternate arrangement, though characteristic, is not invariable. In the ancestral form all the carpels must undoubtedly have been similar and valve-like, and the processes of reduction and consolidation here assumed to have taken place may well have proceeded by symmetrical stages. But a partial return to the primitive state is very likely to occur through some favourable condition so localized as to be one-sided in its effect.

1 This arrangement, though very exceptional, is not confined to Matthiola. It occurs in the nearly allied genus Moricandia ( $M$. divaricata, Coss.), where also the stigmas are sessile, and probably elsewhere (see below, p. 466).

2 Occasionaily in a wide commissure with two main fibro-vascular bundles the two bundles may diverge so much that a considerable breadth of non-vascular tissue is developed between them, simulating an interpolated valve. That such tissue does not repre-ent a true valve carpel is shown by the entire absence of vascular tissue and by the outline, which is V-shaped at the base instead of having the rounded contour of the true valve. 
6. The conception of the dimorphic carpel removes the anomaly of the 'false' partition and the 'commissural' stigma, and brings into harmony and renders intelligible many facts hitherto unexplained or without significance.

Owing to its smooth polished surface, in addition to the considerable width of the commissures and the massive apex of the siliqua, the glabrous Stock offered exceptionally favourable material for the present investigation, but the conclusions here set forth are applicable to the Cruciferae in general. Moreover, they render intelligible certain facts already well known and others less familiar, the precise significance of which has hitherto not been apparent. In the first place, the nature of the replum is now clear. It is characterized by the same histological features as the valves. But in the rearrangement of the tissues of the median carpels necessitated by the consolidation process, the vascular bundles come to lie more or less in a ring, and the cells, which in the valve form extend beneath the lining epidermis along the whole extent of the loculus and are converted later into mechanical tissue, here become massed on the inner side of the fibro-vascular cord and form at the centre the characteristic fibrous strand. Sometimes, however, the median pair of carpels are arrested in their development before they come into contact, or even before any ingrowth at all has taken place, in which case the ovary remains unilocular. ${ }^{1}$ When there are more than four carpels, the number of septa and the planes (orthogonal or diagonal) in which they will lie will depend upon the number and arrangement of the solid carpels and their relative vigour. In the 5-carpelled siliqua, with one lateral and two diagonal valves and two solid median carpels, the adjustment required generally results in considerable asymmetry. There may be no true septum, but the fusion of the inner bulging surfaces of the two diagonal valves may give rise to one closed loculus and to a second cavity not completely closed in by their free or disrupted edges. In 6-carpelled fruits with alternate arrangement of hollow and solid carpels a $\mathrm{Y}$-shaped partition may be formed by the solid carpels, as was found in one Stock siliqua, and as is represented in one of de Candolle's ${ }^{2}$ 3-valved Lepidium fruits. The presence in another of his figures ${ }^{3}$ of Lepidium, and also in one by Godron ${ }^{4}$ of a 3 -valved Cheiranthus ovary, of a central triangular cavity is presumably due to splitting at the centre in the course of growth. When eight carpels are present, any one of the following conditions may no doubt occur: (I) One pair of the solid diagonal carpels only gives rise to an

1 Constantly, e. g. in Pringlea (2-valved, dehiscent, many-seeded), Enarthrocarpus (jointed, indehiscent, many-seeded), Peltaria (indehiscent, one-seeded), Braya Eschscholsiana, Benth. and Hook., and Clypeola (2-valved, each one-seeded), and in the fertile section of the fruit of Cakile, Crambe, and Myagrum. Exceptionally in many other genera, either partiaily or completely.

2 Loc. cit., Tab. V, Fig. 16.

${ }^{3}$ Loc. cit., Tab. V, Fig. I 7 .

${ }^{4}$ Loc. cit., Pl. XVIII, Fig. 8.

$\mathrm{H}$ h 2 
antero-posterior septum. (2) Each pair forms such a septum. (3) All four converge to the centre, forming four compiete or incomplete septa which lie in the two diagonal planes. The third form, as it happened, was not seen in the Stock, but a Cheiranthus fruit figured by de Candolle ${ }^{1}$ was of this type.

This reversion to a multicarpellary condition, which has been observed in at least nineteen Cruciferous genera, ${ }^{2}$ in a few fruits, in an individual here and there, may sometimes prevail through a large part of the individual. In plants of Lepidium sativum, L., raised by de Candolle from seed of multicarpellary Abyssinian parents, he found trilocular fruits almost as abundant as those of normal structure. ${ }^{3}$ In the two forms originally named Tetrapoma barbaraefolia, Turcz., and Holargidium Kusnetzozeii, Turcz., but now recognized merely as many-carpelled variants of Nasturtium palustre, DC., and Draba (? hirta, L.), respectively, the exceptional fruits are exhibited throughout the whole or the greater part of the inflorescence. Offspring from seed of Tetrapoma individuals have been found to exhibit the reversionary character. According to Hooker, ${ }^{4}$ however, this is not invariably the case, and as a criterion of species, therefore, the character is useless. The reappearance of the character in the second generation of de Candolle's Lepidium plants grown in the spring, and its non-appearance in the third generation raised in the autumn, are of particular interest, as showing the dependence of the character upon conditions, as is indicated also in the Stock (see above, p. 457). The herbarium material of Tetrapoma which I was able to examine had mostly four valves, alternating with four solid carpels forming complete septa, but as many as five or even six of each occurred in individual fruits. In the specimen figured by Baillon, however, the septa are incomplete. ${ }^{5}$ The short style, as in comparable cases in Cheiranthus, showed a corresponding increase in thickness. From the strictly radial type of symmetry exhibited by these fruits, it is clear that this multicarpellary condition does not arise through the morphological abnormality known as" twinning'. ${ }^{6}$ Rather it affords us a real glimpse of

1 Loc. cit., Pl. XVIII, Fig. 9.

${ }^{2}$ Alyssum incanum, L., A. libycum, Coss, Arabis alpina, L., Brassica Napus, L., Brassica oleracea, L., Capsella Bursa-pastoris, L., Cheiranthus Cheiri, L., Draba nemorosa, L., Diplotaxis muralis, DC., D. tenuifolia, DC., Erophila vulgaris, DC., Erysimum pannonicum, Crantz, E. repandum, L., Fortunia Garcini, Shuttl., Iberis sempervirens, L., Lunaria anmua, L., L. rediviva, L, Matthiola incana, R.Br., Megacarpaea, Peltaria alliacea, Jacq., Raphanus sativus (caudatus), L, Ricotia Lunaria, DC., Sinapsis arvensis, L., Thlaspi arvense, L. (For Erysimum repandum see Reichenbach, Icones, ii, Tab. LXXIV, Fig. 4406; for the rest see references in Penzig's Pflanzen-Teratologie.

3 Monstruosités végétales, $\mathrm{p}$ I 3 .

${ }^{4}$ Gen. Pl., i, 1862, pp. 83, 967.

5 Nat. Hist., iii, p. 184 , Fig. 213.

6 The phenomenon of 'twinning' is not uncommon among the Cruciferae. I have elsewhere suggested (Journ. of Genetics, vol. xi, I, I92 I) that the occasional references in the early literature to the occurrence of semi-double flowers in the Stock are probably to be thus explained, as also I have no doubt is Darwin's statement that he had himself seen single and double flowers on the same Stock 
the past. For there can be no doubt that in all these cases we are witnessing the reappearance of an ancestral character exhibited to a very slight degree and only sporadically in the several genera cited above (see foot-note, p. 464), but here manifested to a remarkable extent. These occurrences, in fact, furnish concrete evidence that the progenitors of the present-day type of Crucifer were possessed of a many-carpelled ovary, and thus approached more nearly to the construction of some existing types among the Papaveraceae. Before leaving this part of the subject, it may be well to emphasize the point that the conception of two kinds of carpels is essential to the understanding of the relation of these multicarpellary fruits to the typical siliqua, and of the arrangement and position of the valves, especially in 3 -valved fruits, in which the unpaired valve is generally lateral, though occasionally median. In the former case the suppression or consolidation of one lateral valve has been balanced by the production of hollow instead of solid carpels in the diagonal planes on that side. Similarly, in the latter case the development of one valve in the median plane has been compensated by the consolidation of the lateral carpels and the assumption of valve form by the two carpels in the diagonal planes. Several observers who have declared their adherence to the $G_{2}$ formula for the typical siliqua nevertheless cite these exceptional fruits as having a phylogenetic significance and as evidence of a fuller ground-plan composed of four orthogonal valve carpels. It is perhaps the contradiction involved in this position-for such a ground-plan does not satisfactorily account for the 3 -valved siliqua - which has delayed recognition of the real character of these fruits now shown to be derived from a $4+4$ ground-plan, and has caused them to be dismissed as 'sports' or monstrosities. On the other hand, Lindley, Kunth, and Klein, who recognized the commissures to be carpels, for whatever cause, do not appear to have extended their observations to these multicarpellary ovaries. How many cases of so-called 'sports' appearing under cultivation, or as the result of some other change in the external environment, are in reality the expression of some ancestral phase reappearing under a favourable combination of circumstances is a question which needs further investigation.

But the dimorphic nature of the carpel does more than rehabilitate the septum; it removes that most crucial difficulty, the commissural stigma. Observation shows that in the great majority of the Cruciferae the valve carpels have ceased to fulfil the receptive as well as the reproductive

plant (Animals and Plants, p. 38I). Instances are also recorded by Godron (loc. cit., p. 303 ) for Brassica oleracea, L., by Eichler (Flora, 1872, p. 333) for Brassica Napus, by Wille (Bot. Centralbl., xxvi, 1886, p. I2I) for Capsella Bursa-pastoris, L., and figured by Schnizlein (Iconographia, Fig. 18I $a$, Figs. 39, 40) for Raphanus. The difference in orientation of multicarpellary fruits arising from this cause which show isobilateral symmetry, from those due to reversion which are constructed on a radially symmetrical plan, is illustrated in Godron's figures of Brassica oleracea. (Compare Figs. 1 and 2 with Figs. 6 and $7, \mathrm{Pl}$. XVIII, loc. cit.) 
function. The two solid carpels alone, in these cases, are prolonged upwards to form a style, consequently the lobes bearing the stigmatic surfaces are naturally centred, as is particularly well seen, e.g., in the Wallflower (Cheiranthus Cheiri, L.) (Fig. 40), over the two so-called commissuresnow proved to be not true commissures, but consolidated carpels. ${ }^{1}$ The few remaining genera fall under two heads: $(a)$ those in which valve carpels as well as solid carpels are prolonged to form the style, and therefore presumably form part of the capitate stigma, as in Biscutella (valves separating but indehiscent) (Fig. 37) and Guiraoa arvensis, Coss. (indehiscent) (Fig. 4I); (b) those with the style short or wanting, in which the valves, but little shorter than the solid carpels, bear the stigmatic papillae, as e. g. Matthiola incana, Moricandia, and possibly Loncophora. Hence, we need no longer subscribe to the time-honoured morphological fiction of the commissural stigma. In place of it, we have clearly shown to exist a morphological dimorphism sufficiently elastic to permit of a considerable degree of physiological interplay without change of ground-plan. It was the serious difficulty involved in the acceptance of a genuine commissural stigma which led Lindley nearly a hundred years ago to suggest that the Cruciferous placentae are in reality independent carpels (see above, p. 455). He was led to this view through a comparison of the typical siliqua, with an ovary, with four stigmas of Eschscholizia californica, Cham., which latter type of gynoecium he conceived might arise if the structures represented by the Cruciferous valves were contracted to mere threads producing partially aborted stigmas, and if the placentae, on the other hand, were widened to become the placentiferous valves of Eschscholzia, bearing well-developed stigmas (Figs. 38, 39). Though Lindley thus arrived at a correct interpretation of the siliqua, his evident conception that similarity of function indicated morphological identity caused him to miss the true homologies, and to propound his solution in a way which introduced a new difficulty almost as serious as the one it removed, for his scheme involves a shift of the orientation through $90^{\circ}$. Moreover, the replum is not double, as he supposed. Hampered by this idea of morphological equivalence, although he considers the possibility that his conjectured four carpels in Eschscholsia might produce four placentae and thus account for the multiple rows of ovules in this genus, he inclines against this view. It must further be noted that these theoretical considerations were unsupported at the time by any actual evidence, and that they still left unexplained other apparent contradictions. Thus, the unsoundness of the premises caused the correctness of Lindley's conclusion regarding the Cruciferae to remain unperceived, and botanical opinion has perforce acquiesced in the highly unsatisfactory alternative, the commissural stigma and the spurious partition. Only by

1 It must be through some error that Cheiranthus is instanced by Eichler as a case where the stigma lobes alternate with the placentae (Bliithendiagramme, ii, p. 204). 



36
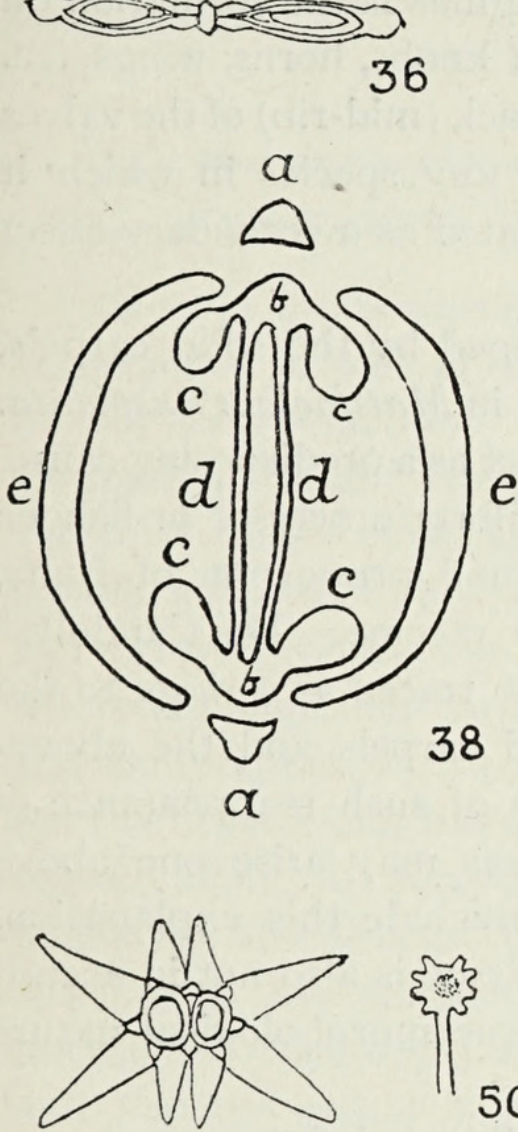

41

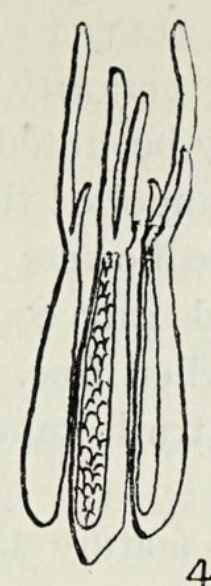

46

$a$

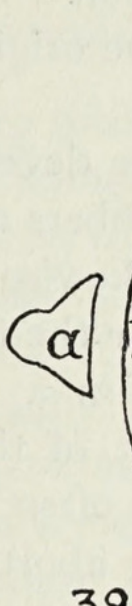

39



51
47


40

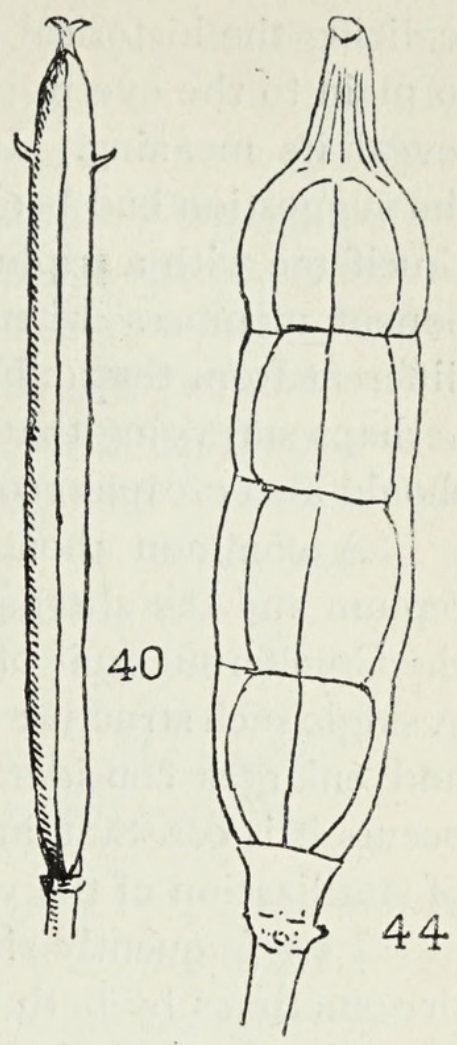

Figs. 36-7. Biscutella frutescens. 36. Transverse section of the fruit, showing the ovulebearing valves. 37 . Ripe fruit, showing that the valve carpels contribute to the formation of the short style. 38,39 . (Diagrammatic.) Showing Lindley's idea of the possible derivation of the Eschscholzia type from the Cruciferous ground-plan. 38. Cruciferous ground-plan (a, $a$, position of stigmas ; $b, b$, placentae ; $c, c$, ovules ; $d$, $d$, double septum; $e, e$, valves). 39. Ground-plan of Eschscholzia ( $a, a$, perfect stigmas ; $b, b$, sides of pericarpium connecting the placentae ; $c, c$, ovules ; $d, d$, abortive stigmas; $e, e$, line of pericarp corresponding with the abortive stigmas). 40. Siliqua of Cheiranthus Cheiri, showing commissural outgrowths. 4I. Transverse section of the fruit of Guiraoa arvensis. 42, 43, 49. Rapistrum. 42. Fruit of $R$. perenne, showing the smaller basal segment and the larger upper one. 43. Transverse section of the upper segment, showing the eight valves. 49. Transverse section of the lower segment of the fruit of $R$. aegyptium. 44. Manyvalved lomentose fruit of Enarthrocarpus clavatus. 45. Brassica cheiranthiflora, siliqua cut across, showing the 3-ribbed valves. 46-7. Eschscholzia crocea. 46. Fruit with eight stigmas. 47. Ovary with two single filiform stigmas over the commissures and two 5 -lobed plates over the valves. 48. E. californica, portion of fruit, showing ten ribs and numerous rows of ovnles. 50-51. Corydalis. 50. Stigmatic disc of C. bulbosa with eight processes. 51. The same of C. fabacea. (Figs. 36, 37, 44 after Cosson ; 38,39 after Lindley; 4I after Willkomm ; 42, 43, 45, 50, $5^{\mathrm{I}}$ after Reichenbach ; 46, 49 after Baillon ; 47 after Payer ; 48 after Hooker ; 40 original.) 
realizing the historical position can one come to understand why evidence so plain to the eye in the overwhelming majority of the Cruciferae failed to reveal its meaning. In passing, it may be noted that a few years earlier the suggestion had been made by de Candolle ${ }^{1}$ that we have to deal in the Cruciferae with a triple flower (i. e. three flowers in one), and that its component members when thus combined can conceivably assume a shape different from that exhibited by them when free. Thus presented, it is not perhaps surprising that the element of truth contained in this explanation should also escape recognition.

A common though less constant feature than the presence of the replum and the alternate position of valves and stigmas is the formation on the Cruciferous fruit of excrescences in the form of knobs, horns, wings, \&c. A single such structure is frequently formed on the back (mid-rib) of the valves and enlarges considerably after fertilization. In any species in which it occurs it is constant, and may perhaps have originated as a secondary effect of sterilization of the valve carpel.

Less frequently similar outgrowths are developed by the solid carpels, or sometimes by both valve and solid members as in Matthiola tricuspidata. Possibly consolidation of the carpel may likewise act as a predisposing cause. The Wallflower is a puzzling exception, for the filiform processes or flanges which appear on the sutures occur only in a small proportion of fruits, generally among those in the lower part of the raceme. De Candolle ${ }^{2}$ suggested that these structures, which can often be traced as a ridge to the base of the commissure, might represent aborted carpels, and the abovementioned localization might well connote a case of such reappearance of a lost member, but the fact that several processes may arise one above another on the same suture seems definitely to preclude this explanation. Moreover, the fact that they contain no vascular tissue is also not in accord with such an interpretation. It seems that their true morphological nature has yet to be determined.

In other types the fruit may constantly exhibit a definite number of processes or wings, or it may show an unvarying number of conspicuous longitudinal parallel ribs. In illustration we may cite the following :Menonvillea (fruit 4-winged), Hexaptera (6-winged), Guiraoa arvensis, Coss. (8-winged) (Fig. 41), Decaptera (IO-winged); species of Isatis (6-IO-valved) (Figs. 59-6I); species of Brassica, Sinapis, Sisymbrium (valves 3-nerved) (Fig. 45); species (dehiscent) of Carrichtera and Boleum (with 3-6-ribbed valves); species (indehiscent) of Rapistrum (Figs. 42, 43, 49), Enarthrocarpus, and Raphamus, with from 6 to 24 ribs, ridges, or sutural lines on the fruit. These many-ribbed siliquas at once bring to mind the ro-ribbed siliquiform fruit of Eschscholizi.

1 Théorie élémentaire de la botanique, and ed., I8I9, p. I44.

2 Monstruosités végétales, p. I5. 
It has already been recalled that it was from a comparison of the Cruciferae with Eschscholsia that Lindley was led to the view that the Cruciferous placentae are in reality independent carpels. It is, therefore, fitting that it should be from further comparison with this same genus that we are enabled to obtain new light on the construction of the many-ribbed siliqua. Lindley visualized the fertile carpel contracted to a placentiferous cord, but he failed to perceive the consolidation which produces the multicarpellary valve, and so missed the significance of the 10-ribbed character in both the Cruciferous and the Papaveraceous gynoecium-proof, as will appear, of the presence of a corresponding number of solid carpels in both families.

\section{Reduction and consolidation shown to have occurred in like manner in the Papaveraceae, Fumariaceae, Capparidaceae, and Resedaceae.}

Now a multicarpellary ovary in Eschscholsia would be a quite natural construction in view of the numerous carpels present in several other genera of the Papaveraceae. It is to this family, and the allied Fumariaceae, Capparidaceae, and Resedaceae, that we must now extend the inquiry, since the solid carpel explanation of the so-called commissural stigma must, we should suppose, apply equally to them. And this we find to be the case. For example, on the one hand may be cited Platystemon californicus, Benth., where the numerous carpels are all of the valve type with single-line sutures, and the stigmas, as we should then expect, superposed upon the midribs. On the other hand, the numerous genera with stigmas alternating with the valves, again in accordance with expectation, show double-line sutures; hence the distribution of the stigmas is not in reality exceptional, except in so far as they are borne by the solid carpels only. Among such may be mentioned Bocconia, Chelidonium with 2, Roemeria with 4, and Meconnpsis and Papaver with 4-8-12 valves. The fact that in the band form of stigma characteristic of Papaver and its allies each stigmatic band can be seen to be double, was considered by Eichler as decisive against Lindley's view that the placentae in such cases represent whole carpels. But the solid carpel, although so contracted as to form merely a radial sheet of tissue, must yet be conceived to possess two edges like the expanded valve. Moreover, the ends of each pair of parallel stigmatic lines are continuous at the periphery of the stigmatic plate so that they form a very narrow $V$, a shape we might expect if compression were accompanied by a shearing action forcing inwards the tissues of the carpel lamina on either side of the midrib. It thus becomes unnecessary to make the entirely unsupported assumption required on Eichler's view that fusion occurs between every pair of neighbouring half-stigmas.

To return, however, to the case of Eschscholzia. The ovary in this 
genus is always regarded as dimerous. Prantl and Kundig ${ }^{1}$ describe it as composed of two carpels with 2-4 stigmas, and the fruit as dehiscing either septicidally or by the two valves becoming detached from the placentae. Figures are given of an ovary of four segments, with two pairs (one longer and one shorter) of filiform stigmas, and of a ripe, split, two-valved fruit with a row of seeds on one side only of each valve, both from E. californicus (Figs. $82 \mathrm{~B}$ and $83 \mathrm{C}$ ); also one (from Baillon ${ }^{2}$ ) (Fig. 46 ) of a fruit of $E$. crocea showing two valves with triple stigmas, the valves being detached from the two placentae, each of which carries a single stigma. Finally, in addition to two filiform stigmas, two others of 5 -lobed plate-like form are shown by Payer $^{3}$ in a drawing of E. crocea (Fig. 47). On the accepted formula of $\mathrm{G} 2$ there are several points in these statements and figures which require to be explained away, viz. the varying number of stigmas $(2,4,8,12)$; the two modes of dehiscence (the single split into two seed-bearing valves, and the double split into two seedless valves and two seed-bearing placentae, with the associated difference in length of the two pairs of stigmas); the numerous confused rows of ovules on the placentae. In order to arrive at a true interpretation of these somewhat contradictory relations, we must take into consideration the following facts:

I. All botanists to-day are agreed that Eschscholzia is closely related to the two genera Dendromecon and Hunnemannia, and that these three forms stand very near to a group in which the carpels are more than two, viz. Platystigma with three and Romneya and Platystemon with six to ten or more.

2. Eschscholzia ${ }^{4}$ (Fig. 48), Dendromecon, and Hunnemania are all distinguished by having fruits with ten conspicuous ribs. In the intervening flat sections of the roughly Io-sided ovary there is an additional subsidiary vascular strand.

3. Dehiscence of the fruit in Dendromecon and Hunnemannia is by the two valves becoming detached from the two thread-like placentae, which form a frame (replum) as in certain of the Capparidaceae.

4. The two stismas of Dendromecon, though stated to have three lappets ('Pflanzenfamilien', iii, 2, p. I 38 ), are shown in the drawing (loc. cit. Fig. 87 C, also 'Bot. Mag.', t. $5^{\text {I } 34) ~ t o ~ b e ~ i n ~ r e a l i t y ~} 5$-lobed ; ${ }^{5}$ that of Hunne-

1 Pflanzenfamilien, iii, 2, pp. I38, I 39 .

2 Nat. Hist., iii, p. II 8 , Fig. I 40.

3 Organogenie, Tab. XLV, Fig. 38 .

${ }^{4}$ See Bot. Mag., 56 (1829), t. 2887 .

5 On the ground that he himself had never found 5 -lobed stigmas in the plants which he examined, Fedde asserts that these drawings must be incorrect (Pflanzenreich, iv, 104, p. 39). But Dendromecon may well show transition stages like Eschscholzia. Not only is there no ground for assuming these figures to be incorrectly drawn, but in the light of what has been made clear in the present account, such a 5 -lobed outline to each valve stigma might well be expected from the outline of the ovary. 
mannia is described as 4-lobed ('Pflanzenreich', iv, I04, p. 144 ; see also 'Bot. Mag.', I 83 I, t. 306 I).

None of these facts are in good accord with a bicarpellary construction, and some are clearly incompatible with it. But in the light of what we have now learned from observation of certain Cruciferous genera, they can be satisfactorily harmonized and explained. There is no doubt that in Eschscholzia, as also in Dendromecon and Hunnemannia, we have not less than ten solid and ten other carpels present. ${ }^{1}$ The processes of sterilization and consolidation, which have reached their height in the Chelidoneae among the Papaveraceae and in the Cruciferae generally, are here seen actually in progress. The ten solid carpels are indicated by the ten ribs of the ovary wall, and further, by the two 5 -lobed stigmas seen in Payer's figure of Eschscholizia and again in Dendomecon. In the exceptional condition (hitherto unexplained) represented in Baillon's figure of a fruit of E. crocea, we have a stage in which division of labour among the carpels has reached a point at which six of the solid and eight, if not all, of the other carpels have already become infertile, though the former have retained their stigmas. The two solid members on either side of each median carpel, and, perhaps this same member as well, have remained ovuliferous, but show a decline of the stigmatic function, each median trio forming between them only a single stigma, which is less well developed than that of the middle member in each lateral group of three, but longer than that of its companion (outside) members. On dehiscence each triplet of sterile solid carpels, together with the contiguous valves, becomes detached as a single lateral compound valve. We see the next stage in the 4-sutured ovary with four stigmas, where the stigmas of the four outside solid carpels of the two triplets have now entirely disappeared. Finally, in the 2-stigma-bearing, 2-compound-valved fruit dehiscing by a single split, the ovuliferous carpels have also lost their stigmas, leaving only the two of the lateral solid carpels. The range thus illustrated within this one species is exhibited throughout the genus. Among more than 120 forms listed by Fedde ('Pflanzenreich', loc. cit.) the enormous majority have four stigmas generally of unequal length, apparently the most stable phase to-day. But of the rest one is cited with a doubtful six, two with eight, one with eight to ten, one with a doubtful twelve, while at the other end of the scale some three or four have reached the limit of reduction (2). In face of these facts, whether these numbers are invariable or only predominant for each type, $\mathrm{G} 2$ becomes a meaningless symbol. Dehiscence usually occurs in the median plane. As it appears to be very usual for the split to arise so that one median carpel is left attached to each compound valve, the latter would show more rows of ovules on the one margin than on the other in a form where the

1 The total of twenty is based on the supposition that each median flat face is composed of but one carpel. Only if this were not so would the number be higher. 
adjacent solid carpels were also ovuliferous, as has been assumed to be the case in such plants as those figured by Hooker and Baillon, though ordinarily the median pair alone are fertile. In this way the massing of the ovules, hitherto a puzzling feature, now becomes intelligible. Owing to the threadlike character and close juxtaposition of the placentae, the impression is given that two placentae, superposed upon two ribs, are each crowned with some four or five rows of ovules, as depicted in the illustration referred to above (Fig. 48). ${ }^{1}$ Presumably these placentae are placed on either side of the mid-line of each of these two ribs, as is characteristic in solid carpels.

Both the Fumariaceae and Capparidaceae include some genera which show two solid and two valve carpels, and dehiscence after the manner of the typical Crucifer, but here the ovary remains unilocular, the replum being merely a frame-a condition rare in the Cruciferae, but characteristic of certain Papaveraceae (see above, p. 470). These features are well seen in species of Corydalis (Fumariaceae) and in Cleome (Capparidaceae). In both families, however, forms are also to be found which point to this type of gynoecium having resulted from consolidation and reduction precisely as in Papaveraceae and Cruciferae. In Capparis spinosa, L., instead of $\mathrm{G}_{4}$ (two hollow and two solid), we find G I6 (eight of each); and in Morisonia, another genus having a berry instead of a siliquiform fruit, G 8 (four of each). Also it seemed not impossible that these same processes might account for the great variation in number of the stigma lobes which is to be found in the Fumariaceae. In some forms there are two divaricate lobes placed over the placentae, in others (species of Corydalis) the style terminates in an erect plate-like structure with several small lappets, the number, though varying (4-6-8), being constant for any species (Figs. 50, 5I). But though the vascular cord of the solid carpel sometimes appears to consist of three bundles (Dicentra), and the vascular strands of both valve and solid carpels pass up into the stigmatic plate, the increase in number of the vascular elements makes it difficult to determine any precise relation between the bundles and the lappets which are not themselves vascular.

The Resedaceae, though having an appearance of greater uniformity than the families already considered, nevertheless present an equally interesting and instructive series as regards the construction of the gynoecium. The number of carpels is stated to vary from two to six. They may be joined partially or completely, or altogether free. In Reseda the valves usually terminate in points which alternate with the placentae and bear the stigmas. In $R$. odorata, L., however, according to Buchenau, ${ }^{2}$ the stigmas are placed midway between the valve points, i. e. they are over the placentae, whilst in the giant strain of this species commonly cultivated it is not unusual for stigmatic papillae to be developed in both positions.

1 Bot. Mag, loc. cit.

2 Bot. Zeit., I853, Beiträge zur Morphologie von Reseda. 
As Buchenau truly remarks, the stigmas do not appear to be tied to any particular morphological position, but he offers no explanation of this surprising fact, although in this genus they are so distant from one another that on question of fusion between neighbouring half-stigmas can arise. Another interesting fact from our present view-point is that in some species each placentiferous cord remains intact throughout its length, whilst in others it bifurcates above, a character of some importance in determining relationships. Both these features, viz. the variable position of the stigma and the behaviour of the placenta, hitherto unaccountable and apparently without import, now become significant and easy of explanation, for here too we have distinct evidence of consolidation resulting in dimorphism of the carpels. In such forms as $R$. luteola, L., $R$. glauca, L., R. complicata, Bory, $R$. virgata, Boiss. and Reut., the carpels are all of the valve type. Separation of the conjoined edges of the carpels above is accompanied by a preparatory separation of the two ovuliferous strands-the double placenta bifurcates. In such types the stigmas occupy a position over the midribs of the valves. In other species in which the double placenta remains whole, as e.g. in $R$. lutea, L., $R$. alba, L., $R$. phyteuma, L., the sutures present a double contour line-they are in fact not merely placentae but whole (solid) carpels and hence remain intact. In the light of this fact it is comprehensible why in those species which have a line of hairs or protuberances on the midrib of the valve, a line of these structures should also be present on the suture (the midrib of the solid carpel) as in $R$. arabica, Boiss. It is now also clear why even the young syncarpous gynoecium in Reseda is open at the top. The valve carpels are joined to the intervening placentiferous solid carpels, but the latter do not extend to the same height as the valves ; consequently where the solid carpels cease, the valves are disjoined and the ovarian cavity is not closed in. That the same condition obtains in the species with the few carpels present all hollow may be due to the form of the valve having become fixed before the disappearance of the solid members. We see in the $R$. odorata, L., type with its stigmas on the solid carpels, and the $R$. luteola, L., type with valve stigmas, an example of the same interchange of functional activity as has been shown to occur in the other families treated above. Finally in Randonia, where we have in reality not $\mathrm{G}_{2}$ but $\mathrm{G}_{4}$ (two solid and two hollow), we find a construction which is the counterpart of the typical siliqua, with this difference, that here it is the lateral carpels which become solid and the median which remain hollow. The general plan is precisely the same as in the Crucifer, but in Randonia there is great development of the flower in the median plane on the posterior side, and the plane in which consolidation takes effect is (? consequently) shifted to that in which the lateral carpels lie.

With the clue furnished by the dimorphic carpel yet another mystery is dispelled, for we are now able to interpret the extremely interesting and 
hitherto unexplained phenomena exhibited by such forms as Ceratocapnos (Corydalis) heterocarpa, Ball. (Figs. 52, 53), among the Fumariaceae, and Aethionema heterocarpum, J. Gay, and Diptychocarpus strictus, Trautv., among the Cruciferae. These plants are peculiar in that they appear habitually to produce two kinds of fruit in the same inflorescence. Those first formed are short, thick, indehiscent, composed of four similar (hollow) carpels; those which succeed them are more elongated, slender, dehiscent, two of the carpels becoming detached as valves from the other two, which have undergone a partial transformation towards the solid type. The significance of this heterocarpism is now fully apparent. We have exhibited in these plants as a fairly constant feature a transition comparable with that observed occasionally in Eschscholizia (see above, p. 47I). The process of consolidation is taking place before our eyes!

It is a striking fact that in these heterocarpic species among the Cruciferae and Fumariaceae it is the ancestral type of fruit composed of uniform hollow carpels which does not dehisce, whereas the later-evolved form in which some carpels have become solid is able to split. Can it be that differentiation into valve and solid carpels provided an easier and more reliable method of securing the opening of the fruit than rupture of the fruit wall at a spot which, though representing a junction of (valve) carpels, perhaps offered insufficient tissue differentiation to secure invariably the initiation of a split? Or has this modification of some of the carpels come about in the course of, and in association with, evolution from a primitive one-or few-seeded fruit in which dehiscence was unnecessary and perhaps did not occur, to a many-seeded condition in which it was essential? These questions we can scarcely hope to answer until a more exhaustive study of the structure of the gynoecium in these families has been carried out.

It has now been sufficiently made clear that in certain families of the Rhoeadales evolution has been accompanied by processes of reduction and consolidation of members of the gynoecium, leading to the production of two kinds of carpel, the hollow and the solid, and that in the dry dehiscent type of fruit consolidation has sometimes occurred without (apparently) a reduction in number, and has led in these cases to the formation of the compound (many-carpelled) valve. We can henceforth eliminate from the scheme of construction the false partition and the commissural stigma. Furthermore, we obtain a rational explanation of the hitherto unexplained occurrence of dimorphic fruits which are met with in many types, either as a rarity, or so constantly as to have been regarded at the outset as of generic value. In them we see the reappearance momentarily or for a longer space of some stage of the phylogenetic history. 
8. A cursory survey of the Ericales, certain Malvaceae, and some isolated genera which are held to have commissural stigmas, leads to the same conclusion. The commissural stigma also not a reality in the Orchidaceae, the synoecium being composed of six carpels $\left(\mathrm{G}_{3}+3\right)$.

The elimination from the Rhoeadales of these anatomical anomalies, and the acceptance in their place of the differentiation of two kinds of carpels and of a certain interplay between them, necessitates at least a brief consideration of certain other unrelated families in which a similar disposition of the stigmas or mode of origin of the dissepiments has been held to prevail. Chief among these are the large group of families included in the series Ericales, the Orchidaceae and certain of the Malvaceae. To deal adequately with these cases within the limits of a single paper is impossible. It can, however, be stated at once that an examination of even a few types has already shown clearly that the same processes of reduction and consolidation have been in progress in these diverse groups as in the Rhoeadales. It is therefore proposed to conclude the present account with a brief reference to one Monocotyledon family, and to present the evidence in the case of the other families in a later communication. We will, therefore, very briefly consider the Orchidaceae from the present standpoint.

A perusal of Eichler's statement of the facts regarding the Orchid gynoecium ('Blüthendiagramme', ii, p. I 82) and a consideration of the figure there given (Fig. I08) of a cross-section of the ovary of Cypripedium Calceolus, L., make it difficult to understand how any one not already committed to the commissural-stigma view and hence concerned to bring all facts into line with it, can fail to realize that the six structures composing the Cypripedium gynoecium, structures fundamentally equivalent in everything but size, represent six individual carpels, three of a pseudo-valve shape alternating with three which have become solid. Of the fact that in some Orchidaceous genera three of the six structures- ' Z wischenstücke', as Eichler terms them-are sometimes wanting, he offers no explanation. In the light of our conclusions in regard to the Rhoeadales we have a clue to this varying conformation within the Orchid family. The full Orchidaceous ground plan is undoubtedly $\mathrm{G}_{3}+3$, but in existing forms where all six are present one whorl of carpels has become solid and sterile, as can be seen from Figs. 54, 55, showing the appearance of the ovary of Calanthe vestita, L., and Cattleya labiata, L., in cross-section. A similar condition is depicted in the figures of the cross-section of the gynoecium of Selenipedilum, Phragmopedilum, Paphiopedilum, Cypripedium, and Trichopilia fragrans, Reichb., in 'Pflanzenreich', iv, 50, p. 22, Fig. 12 A, B, C; also 'Pflanzenfamilien', ii, 6, p. 82 , Fig. 83 E, F, G, and p. 194, Fig. 208. The ripe fruit, generally a capsule, splits more or less completely into three broad strips (Eichler's 'Klappen') and three narrower ones (his 'Zwischenstücke') (as shown in Fig. 
75, p. 73, Pflanzenfamilien, loc. cit.). A comparison of the above figures reveals the interesting fact that here, as in the Rhoeadales, a certain interplay takes place between the two kinds of carpels, that is to say, the association between form and function is not absolutely rigid. Thus in Selenipedilum three of the carpels are of typical valve form, the edges incurve in the normal manner, and re-entering, bear the ovules on the now free terminal surfaces; the other three carpels are much reduced, quite solid and sterile. In Phragmopedilum there are similarly three carpels of the latter type, but here the remaining three have become decidedly massivethe process of consolidation has already converted them into the pseudo or valve or semi-solid form. They are prolonged to the centre, where they meet, but although still valve-like in outline they exhibit the feature associated with the solid conformation, viz. a shifting of the placenta position. It seems possible that one whorl in this type having become sterile as well as solid, the form of the other has been evolved as a compromise: fertility is retained, but consolidation is arrested at a point which leaves enough of the primitive form to satisfy mechanical needs. In Trichopilia the trend of modification is in the same direction; the massiveness of the fertile carpels is even greater, but their later development is not carried so far : they do not meet centrally, hence the ovary remains unilocular. In Cypripedium, on the other hand, this shifting takes place without any marked departure from the valve form, so that the large ovarian cavity is retained with a deceptive appearance of typical parietal placentation. If, as follows from the statement accompanying one of the above figures (see legend to Fig. I2, 'Pflanzenreich', loc. cit.), the three valves in Selenipedilum are formed from the three which in the other genera cited become small, solid, and sterile, we have paralleled here among the carpels a reversal of their ordinary behaviour such as is seen in the Rhoeadales in the case of Randonia (see above, p. 473.) Finally, in such forms as Angraecum and Pleurothallia (see 'Pflanzenfamilien', loc. cit., p. 73) we find the counterpart of the 'compound valve' met with in the Papaveraceae and Cruciferae (see above, p. 474).

If further support for this interpretation of the Orchid gynoecium were needed, we find it in the appearance exhibited by certain of the Alismaceae. No more striking corroborative evidence could be adduced than that presented by the structure of the ovary of Triglochin maritimum, L., with its six fertile carpels, and $T$. palustre, L., with three normal-sized fertile valves alternating with three which, though still enclosing a cavity, are obviously much reduced and on the way to becoming solid (Figs. 56,57 ). ${ }^{1}$ Reduction carried a stage farther would produce the small sterile carpels of the Orchidaceae. Furthermore the parallelism between these reduced carpels and the commissures of the Cruciferous siliqua is shown by the mode of dehiscence. In T. maritimum the ripe fruit splits septicidally into the

\footnotetext{
${ }^{1}$ See illustrations in Flora Londinensis, v, Pls. XCVIII and XCIX.
} 


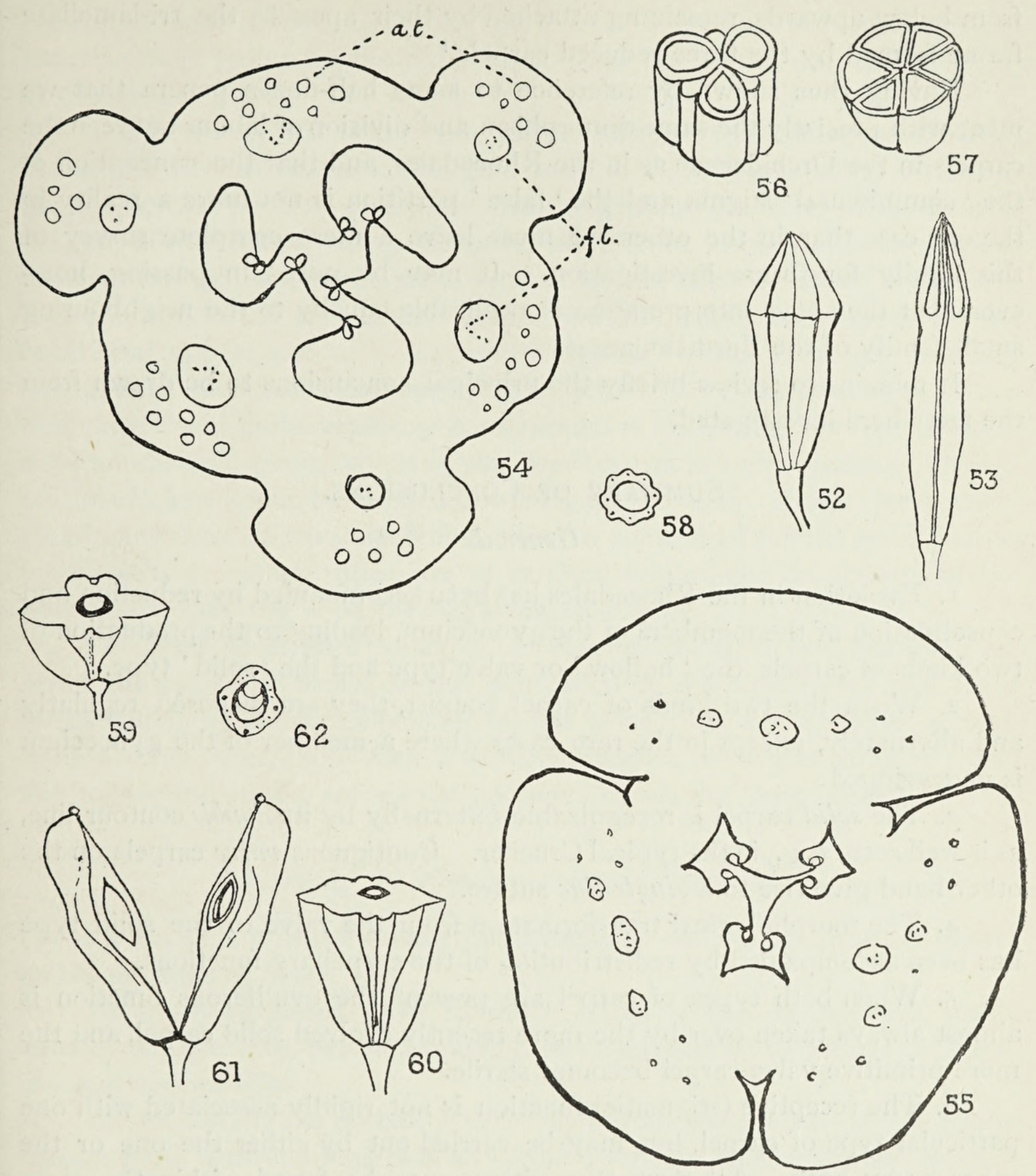

FIGs. 52-3. Ceratocapnos (Corydalis) heterocarpa. 52. Earlier-formed indehiscent, urnshaped fruit. 53. Later-formed dehiscent, siliquiform fruit. 54. Calanthe vestita, ovary in transverse section, showing three solid and three semi-solid carpels (pseudo-valves); a.t., assimilating tissue; f.t., fibro-vascular tissue. 55. Cattleya labiata, ovary in transverse section, structure as in Calanthe; the overlapping of the sunken solid carpels by the pseudo-valves gives a false appearance of single-line sutures. $56-7$. Triglochin. 56. T. palustre, ovary in transverse section. $57 . T$. maritimum, the same. 58. Hypecoum Geslini, 8-ribbed ovary in cross-section. 59-62. Isatis. 59. I. hebecarpa, ovary 6-valved. 60. I. littoralis, ovary ro-valved. 61. The same splitting into two compound valves. 62. I. iberica, ovary in cross-section; the orthogonal carpels form four strong veins; the smaller veins probably represent an equivalent number of intervening carpels here so reduced that they do not form flutings on the surface. (Figs. 52, 53 after Le Maont and Decaisne; 56,57 after Curtis ; 58, 62 after Cosson ; 59-61 after Delessert ; 54,55 original.) 
six component valves, whereas in $T$. palustre the three valve carpels separate from below upwards, remaining attached by their apex to the tri-lamellate frame formed by the three reduced carpels. ${ }^{1}$

Having thus shown by reference to some half-dozen genera that we meet with precisely the same dimorphism and division of labour between the carpels in the Orchidaceae as in the Rhoeadales, and that the conception of the 'commissural' stigma and the 'false' partition is not more a reality in the one case than in the other, we must leave a more complete survey of this family for future investigation. It may be noted in passing, however, that the above interpretation is applicable equally to the neighbouring small family of the Burmanniaceae.

It remains to review briefly the principal conclusions to be drawn from the facts here investigated.

\section{Summary of CONClusions.}

\section{General.}

I. Evolution in the Rhoeadales has been accompanied by reduction and consolidation of the members of the gynoecium, leading to the production of two kinds of carpels, the 'hollow' or valve type and the 'solid' type.

2. When the two kinds of carpel coexist, they are disposed regularly and alternately, except in the rare cases where a member of the gynoecium is undeveloped.

3. The solid carpel is recognizable externally by its double contour line, as is well seen, e. g., in the typical Crucifer. Contiguous valve carpels on the other hand give rise to a single-line suture.

4. The morphological transformation from the valve to the solid type has been accompanied by redistribution of the carpellary functions.

5. When both types of carpel are present, the ovuliferous function is almost always taken over by the more recently evolved solid carpel, and the more primitive valve carpel becomes sterile.

6. The receptive (stigmatic) function is not rigidly associated with one particular type of carpel, but may be carried out by either the one or the other or by both. All three dispositions may be found within the same family, as is the case in the Cruciferae.

7. An alternate arrangement of solid and hollow carpels may act advantageously by facilitating a more complete dehiscence of the fruit than usually occurs where valve carpels only are present. In the latter case separation generally begins from above, and is only partial.

1 The suggestion was made by Gaertner as long ago as $\mathrm{I} 79 \mathrm{I}$, that the three lamellae alternating with the three full-sized carpels might perhaps represent three other members which had been suffocated by their neighbours (De Fruct., vol. ii, p. 26). As Gaertner mentions that the stigmas are sometimes three and sometimes six, possibly we have here a parallel in this respect to the variability in stigma formation which occurs in Eschscholzia californica (see p. 47I). 
8. As a rule the hollow (valve) carpels separate individually from the contiguous solid carpels, but when the number of carpels remains large and many become sterile, a group of carpels may be detached in one piece as a 'compound' valve.

9. The conception of the solid carpel removes the difficulties inherent in the so-called 'commissural ' stigma and the 'false' partition by establishing the normal position of the one and the genuine character of the other.

IO. Furthermore, this conception affords an explanation of various hitherto unexplained phenomena, such as $(a)$ the fairly constant occurrence in some species of two kinds of fruit on the same individual; (b) the occasional appearance of a few multicarpellary fruits in types normally having only the reduced number four; $(c)$ certain more extreme cases, where this exceptional multicarpellary construction is found more or less throughout an individual plant, which on this account has in some instances, though on insufficient grounds, been accorded generic rank. From the present standpoint these exceptional fruits, hitherto considered for the most part as mere sports or monstrosities, are of cardinal importance on account of the light which they throw on the phylogenetic history.

II. Their occurrence points to the conclusion that in each family in the series the course of evolution has proceeded on the same lines: that those forms having numerous carpels all of the valve type and splitting septicidally are the older, those with a reduced number of carpels some of which are hollow and sterile, some solid and ovuliferous, the more recent.

\section{Concerning the Papaveraceae and Fumariaceae.}

I2. Carpels generally numerous (twenty or more), but in some genera as few as three or four.

I3. Many-carpelled fruits in which most of the carpels are sterile usually dehisce into two compound (several-carpelled) valves, as in Eschscholiza and its allies.

14. Evolution has probably proceeded from some form of the Platystemon type, with many carpels all of valve form. Thence in oned irection has arisen the group of the Papavereae, represented at first by forms with many carpels of the solid as well as the valve type, from which the fewcarpelled forms were evolved later. In another direction the Hypecoum types (Fig. 58) with many-veined (-carpelled), generally lomentose or exceptionally dehiscent, compound-valved fruits leading on along one line to the 4carpelled Fumariaceae types: along another perhaps to the Eschscholzieae, still many-carpelled with characteristic replum frame and compound valves.

15. The process of evolution of the solid carpel is to be seen as a regular feature in Ceratocapnos (Corydalis) heterocarpa, Ball. (Fumariaceae), where the earlier fruits are urn-shaped and the later ones siliquiform. 


\section{Concerning the Cruciferae.}

16. The typical gynoecium is composed of four carpels, of which two form sterile valves, the other two which have become solid remaining fertile. In some few genera this relation is reversed. The solid members usually develop centripetally until they meet, and so form a complete partition (the replum), but in other cases the inward growth is arrested at an early stage, so that the partition is wanting or remains incomplete. Thus, the anomaly that from the first moment of their origin the placentae should be as large as, or even larger than, the carpels to which they belong disappears now that these placentae are shown to be independent carpels.

I7. Outgrowths from the upper extremities of the carpels, such as are seen in Matthiola bicornis, DC., M. tricuspidata, R. Br., and Parolinia ornata, Webb, become intelligible when the tetramerous structure of the gynoecium and the division of labour among the two pairs of carpels is realized.

I8. Ovaries of more than four carpels generally show a number of furrows, ridges, ribs, wings, or prominent parallel veins corresponding with the number of the solid or of the valve carpels present. Thus, e.g. in the genus Isatis the contour of the fruit in one species indicates the presence of six valves, in another of ten. From the character of the veining the number of carpels in species of Brassica and Sinapis appears to be sixteen; from the number of wings, sixteen in Guiraoa arvensis, Coss.; from the ribbing, between forty and fifty in species of Rapistrum. It is necessary, however, to distinguish between formations associated with parallel veining and other outgrowths produced as the result of the presence of strong lateral veins, such as the horns in Tetracme, which are not significant of the carpel number.

I9. The presence of this large number of carpels in various lomentose fruits accounts for the formation of the subsidiary loculi at the joints between the seed-containing sections.

20. The stigmatic function is usually restricted to the solid carpels, but it may be subserved by the valve carpels (Matthiola incana) or by both (probably the case in Biscutella).

2I. The evolution of the solid carpel is to be seen in progress in certain types which produce characteristic dimorphic fruits, as e.g. Aethionema heterocarpum, J. Gay, and Diptychocarpus strictus, Trautv.

22. Many types produce a few reversionary multicarpellary fruits, generally, however, only at the beginning of the season and under favourable conditions (observed in some twenty genera).

23. Rarely this reversionary condition may be exhibited throughout the greater part of the plant, as in Tetrapoma (Nasturtium) palustre, Holargidium (Draba), and to a less extent in Lepidium sativum, L. In these cases the character is not inherited in the strict sense, but it may 
nevertheless reappear fairly constantly in the offspring under unchanged conditions.

24. The widespread occurrence of reversionary fruit types indicates that the typical 4-carpelled siliqua and silicula have been derived by reduction and consolidation from an earlier ground-plan, in which $\mathrm{G}=4$ (hollow) +4 (solid); which in turn arose by simple reduction from one composed of a much larger number of both kinds of carpels, this construction being yet again the result of consolidation from an all-valve type with $G$ numerous.

25. This tetramerous constitution of the gynoecium lends considerable support to the view put forward by several earlier observers, that the Cruciferous flower is composed of strictly alternating whorls, and that the ground-plan is $\mathrm{K}_{4} \mathrm{C}_{4} \mathrm{~A}_{4}+4 \mathrm{G}_{4}+4$. The same causes which have led to the consolidation of the two carpels in the median plane have had their effect also on the members of the androecium which also lie in this plane, with the result that the posterior and anterior stamen have completely disappeared. To this same cause may also probably be attributed such inequality in the size of the two pairs of sepals as is not directly accounted for by the asymmetric distribution of the nectaries; while the forces tending to reduction, which in the first instance caused $G \propto$ to become $\mathrm{G}_{4}+4$ (and perhaps $\mathrm{A} \propto$ to become $\mathrm{A}_{4}+4$ ), have led at a later stage to the complete suppression of the last members in the whole series - the second whorl of carpels.

\section{Concerning the Capparidaceae.}

26. The same processes of reduction and consolidation are exhibited here, as in the preceding families, the many-carpelled condition with both valve and solid carpels being exhibited by such forms as Capparis spinosa, L., the final 4-carpelled stage by the section Cleomidiae.

\section{Concerning the Resedaceae.}

27. Number of carpels three to eight. Where the carpels are separate, as in Asterocarpus (6), or with single-line sutures, as in Reseda luteola, L. (3), they are all of typical valve form with the stigma centred over the midrib. In $R$. luteola each edge is bordered by a placenta, hence the appearance of bifurcation as the two separate towards the top where the ovary is open. Where the valve junctions show a double outline the carpels are dimorphic, the extent of cohesion depending upon the height to which the solid carpels extend. As it is the latter which in this case bear the placentae, no bifurcation takes place. The stigmatic function is generally performed by the valve carpels, but in $R$. odorata, L., the solid carpels function as well or sometimes (according to Buchenau) alone. Reduction and consolidation combined reach their limit in Randonia with $\mathrm{G}_{4}$. 
482 Saunders.-A Reversionary Character in the Stock.

The elimination from the ground-plan of the Rhoeadales of the commissural stigma and the fálse partition renders necessary a revision of a number of unrelated families in which the same constructions are held to exist, more especially the whole group included in the Ericales, some genera of the Malvaceae, and the Orchidaceae. Evidence in disproof of the commissural stigma in the Orchidaceae and in support of the formula $\mathrm{G}_{3}+3$ is given in the present account. It is proposed to treat the other families here cited and certain isolated genera in a later communication.

In conclusion, I wish to express my very grateful thanks to Miss D. F. M. Pertz, who made the drawings of the Stock specimens and of the figures cited from other works; also to Miss M. G. A. Campin, who kindly prepared the microscopic sections of the Stock fruits, from which Figs. I9, 28 , and 29 were drawn.

The necessary expenses incurred in connexion with the work have been defrayed by a grant from the Royal Society. 

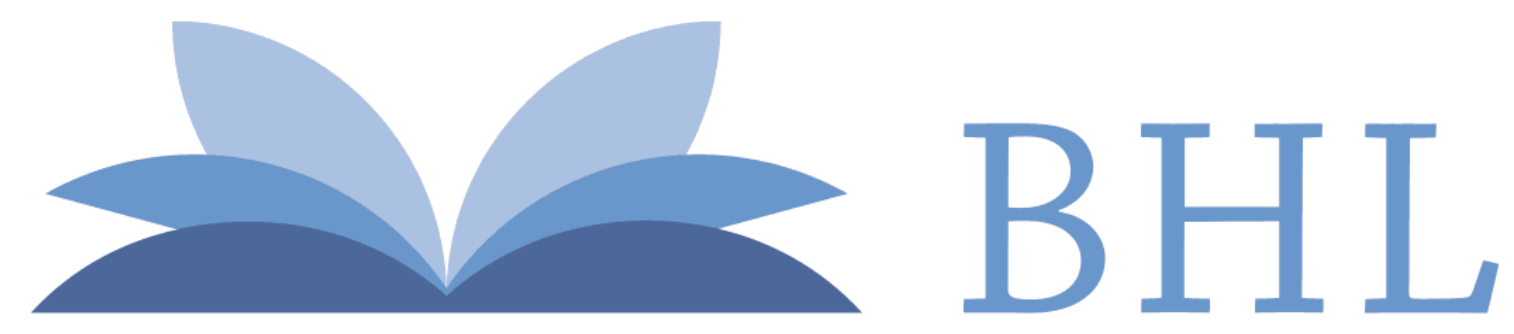

\section{Biodiversity Heritage Library}

Saunders, Edith R. 1923. "A reversionary character in the stock (Matthiola incana) and its significance in regard to the structure and evolution of the gynoecium in the Rhoeadales, the Orchidaceae, and other families." Annals of botany 37, 451-482. https://doi.org/10.1093/oxfordjournals.aob.a089859.

View This Item Online: https://www.biodiversitylibrary.org/item/270686

DOI: https://doi.org/10.1093/oxfordjournals.aob.a089859

Permalink: https://www.biodiversitylibrary.org/partpdf/319096

\section{Holding Institution}

New York Botanical Garden, LuEsther T. Mertz Library

\section{Sponsored by}

BHL-SIL-FEDLINK

\section{Copyright \& Reuse}

Copyright Status: Public domain. The BHL considers that this work is no longer under copyright protection.

This document was created from content at the Biodiversity Heritage Library, the world's largest open access digital library for biodiversity literature and archives. Visit BHL at https://www.biodiversitylibrary.org. 